\title{
Development of effervescent products, in powder and tablet form, supplemented with probiotics Lactobacillus acidophilus and Saccharomyces boulardii
}

\author{
Agnes Izumi NAGASHIMA ${ }^{1 *}$, Paulo Eduardo PANSIERA ${ }^{1}$, \\ Marcela Maria BARACAT ${ }^{2}$, Raúl Jorge Hernán Castro GÓMEZ ${ }^{1}$
}

\begin{abstract}
Probiotics are living microorganisms, which when administered in adequate amounts confer health benefits on the host through a beneficial influence on the intestinal microbiota related to competition and to antagonistic and immunological effects. Thus, the objective of this study was the development of effervescent products (tablets and powder) supplemented with the probiotics Lactobacillus acidophilus and Saccharomyces boulardii, and the identification of the best formulation in terms of viability of these microorganisms. The physical properties of the tablets (compressive force applied, mean weight, hardness, and friability) were assessed, and the viability of the microorganisms in the gastrointestinal tract and their stability during storage were also determined. The results show that the microorganisms remained stable and viable during the 60 -day storage period in the effervescent powder. However, the results indicated that the effect of compression force affected the viability of the microorganisms during the production of the effervescent tablets.
\end{abstract}

Keywords: formulation; stability during storage; viability.

\section{Introduction}

Functional foods play an outstanding role in the food market, demonstrated by the demand derived from the increasing cost of healthcare and the steady increase of life expectancy. Research in this field is considered a high priority, and studies have been conducted to elucidate different food properties and effects in promoting health; these studies often include the analysis of probiotics (OLIVEIRA et al., 2002; BIGLIARDI; GALATI, 2013).

Probiotics are living microorganisms that confer benefits on the recipient health when administered in adequate amounts (FOOD...; WORLD..., 2002). An adequate selection among different probiotic strains has to be performed to allow manufacturing probiotic-supplemented food products. The goal in administering probiotic products is to induce a balanced enteric microbiota, which will have a favorable impact on consumer health. The strain selection process guarantees the survival of these microorganisms in the targeted product during its manufacturing and storage, in addition to ensure that the product will confer adequate technological properties.

The food matrix selected for incorporating probiotic strains should be carefully studied so that an adequate selection of the probiotic strain-food pair is achieved. Verification of compatibility and adaptability among the selected strains and matrixes is fundamental. Several lactic probiotic products, chiefly the fermented as well as some non-lactic products, have been developed as fruit drinks containing probiotics and have been gaining interest in the global marketplace (KOMATSU; BURITI; SAAD, 2008; CHAIKHAM et al., 2013).
Lactobacillus acidophilus are lactic bacteria with weak capacity of lactic acid production. They grow at a temperature range between $20^{\circ} \mathrm{C}$ and $48^{\circ} \mathrm{C}$; its optimal growth temperature is $37^{\circ} \mathrm{C}$. It is a probiotic microorganism with significant beneficial characteristics, as shown by several studies, such as the following: beneficial modulation of the metabolic activity of intestinal bacteria; prevention of diarrhea associated with antibiotics; preservation of intestinal integrity during radiotherapy; stimulation of immune system responses; increase of iron availability; reduction of vaginal bacterial flora; and production of antimicrobial substances that act against other bacteria, viruses, protozoa, and fungi (TENNEY, 1996; FRANCO; LANDGRAF; DESTRO, 1996; GOMES; MALCATA, 2002; MOUNTZOURIS et al., 2009).

Saccharomyces boulardii is a yeast used to treat or prevent several gastrointestinal illnesses. It is efficacious against bacterial infections and inflammatory bowel diseases. It works by releasing in vivo of substances that inhibit certain bacterial toxins and the binding of pathogenic bacteria to the yeast. In addition, this yeast has anti-pathogenic, anti-secretor, and antiinflammatory effects on the intestinal mucosa and decreases the levels of inflammatory cytokines induced by bacteria. When regularly administered via the oral route, the microorganism does not reside in the gastrointestinal tract, but it maintains its viable form in a stable concentration level starting from the third day after administration (BUTS, 2005; MARTINS et al., 2013).

Most probiotic products available on the market are composed of dairy products, and the development of non-

Department of Food Science and Technology, Agricultural Science Center, Universidade Estadual de Londrina - UEL, CP 6001, CEP 86051-970, Londrina, PR, Brasil, e-mail: agnesnagashima@yahoo.com.br

${ }^{2}$ Department of Pharmaceutical Science, Health Science Center, Universidade Estadual de Londrina - UEL, Londrina, PR, Brasil

${ }^{*}$ Corresponding author 
dairy probiotic products is a challenge for the food industry. More studies should be conducted to develop a wider variety of products with probiotic capacity, and these products should maintain their viability after production process and upon consumption. Therefore, the development of water-soluble effervescent products containing Lactobacillus acidophilus and Saccharomyces boulardii (different mechanism of action). These products, powders and tablets, will facilitate daily ingestion of probiotic organisms, which can be added to any liquid product, giving it a pleasant taste and improving absorption. Improved absorption occurs because the carbon dioxide gas stabilizes the gastric mucosa and promotes dissolution of the tablet and its intake, resulting in benefits to consumer health.

\section{Materials and methods}

Lactobacillus acidophilus, lyophilized strain La-5, provided by the Christian Hansen Co. (Denmark), and the yeast Saccharomyces boulardii isolated from the commercial product Floratil $^{\circ}$ (Merck co.) were used in these experiments.

\subsection{Enumeration of lactic acid bacteria and yeast}

Colony enumeration of lactic bacterium and yeast was conducted using the pour plate technique with sterile MRS Agar culture medium (Man, Rogosa, and Sharp, culture medium; brand Merck) and PDA (Potato Dextrose Agar; brand Merck), respectively. Petri plates were aseptically inoculated in triplicate starting from adequate serial dilutions of the samples in a sterile $1 \%$ water + peptone solution. The inoculated plates were then incubated for 72 hours at $37^{\circ} \mathrm{C}$ for Lactobacillus acidophilus, and $25^{\circ} \mathrm{C}$ for Saccharomyces boulardii, and the determination of colony forming units (CFU) was obtained.

\subsection{Probiotic effervescent tablets and powder}

Influence of excipients on the viability of probiotics

To define the composition of effervescent probiotics (in tablet or powder form), an assessment of the component's effects on the viability of the microorganisms was performed using a $2^{(9-5)}$ fractioned factorial with resolution III for a total of 16 experiments and with the probiotic viability as the response. Each of these 16 formulations was added to a $9.0 \mathrm{~mL}$ aliquot of sterile nutrient broth, which was then aseptically inoculated with $0.5 \mathrm{~mL}$ of each culture of $L$. acidophilus and S. boulardii. The 16 experiments were incubated at $30^{\circ} \mathrm{C}$ for 24 hours, and the probiotic microorganism concentration $\left(\mathrm{CFU} . \mathrm{g}^{-1}\right)$ was then assessed. Variation levels of the ingredients used in the $2^{(9-5)}$ experimental design and the codified formulations for assessment of the components' effects on the viability of the probiotic microorganisms are shown in Table 1.

\section{Preparation of effervescent tablets and powder}

Based on the results obtained in the tests assessing the influence of the excipients, the best formulation to manufacture the tablets was achieved. These tablets were then prepared by mixing the ingredients manually and were made using a rotary air compressor (Neuberger, model MN2).

\subsection{Stability of the products during storage (viability of the microorganisms)}

The powder and the tablets were stored for two months at $25^{\circ} \mathrm{C}$ with periodic analysis $(0,15,30,45$ and 60 days) of microorganism viability obtained by the pour plate technique. A $700 \mathrm{mg}$ amount of powder or tablet was added with $6.3 \mathrm{~mL}$ of buffered peptone water (BPW). After 2 minutes, a $1 \mathrm{~mL}$

Table 1. Effect of the ingredients used in the formulation of the effervescent powder on the cell viability (CFU) of Lactobacillus acidophilus and Saccharomyces boulardii in the culture media.

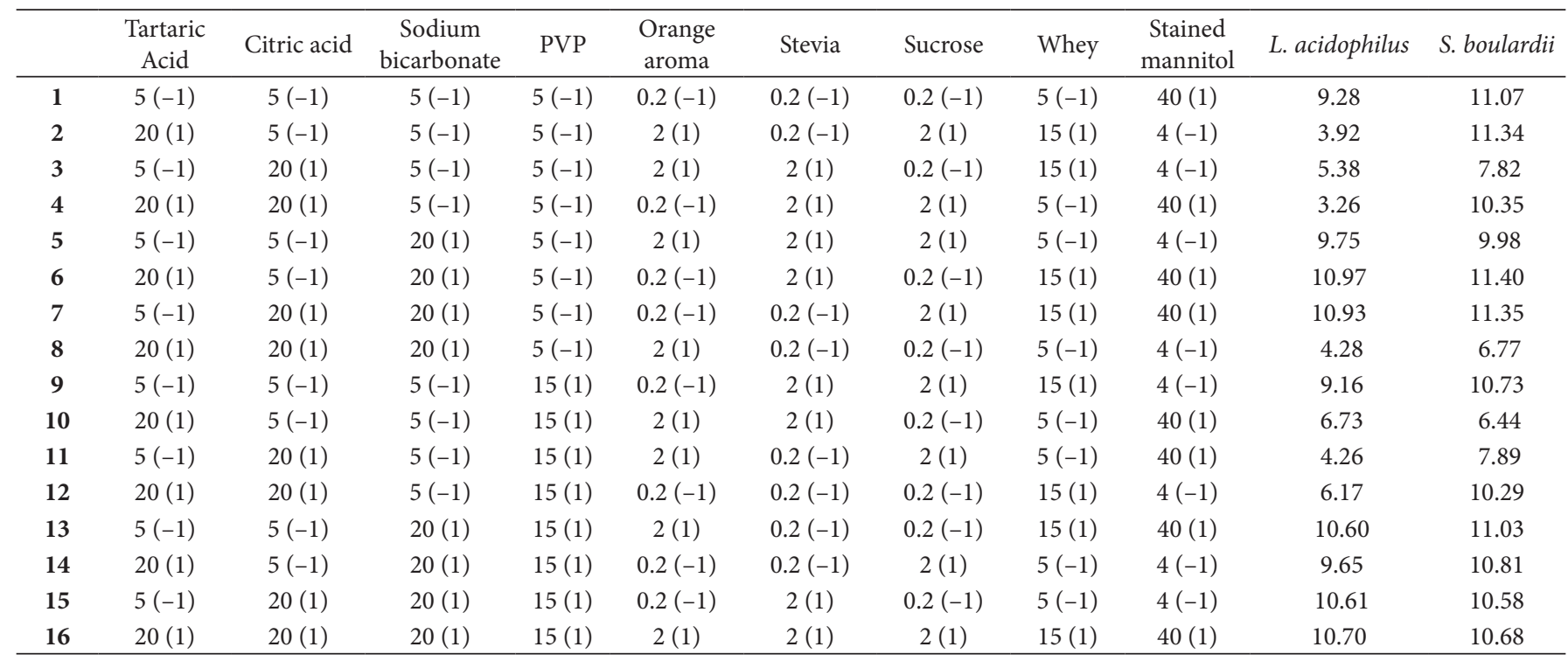


aliquot was collected to prepare a serial dilution for sowing the Petri plates containing MRS Agar culture medium along with the antifungal ketoconazole (666 ppm). The Lactobacillus acidophilus $\mathrm{CFU}$ count was then obtained after incubation at $37^{\circ} \mathrm{C}$ for 72 hours. An additional $1 \mathrm{~mL}$ aliquot was also collected to obtain the CFU of yeast grown on PDA culture medium and after incubation at $25^{\circ} \mathrm{C}$ for 72 hours (in this case, without the addition of the antibiotic, once it was determined that L. acidophilus did not develop under these conditions).

\subsection{Physical properties of tablets}

To determine the physical properties of the tablets, the following tests were performed:

\section{Mean weight}

For this procedure, 10 tablets were individually and randomly weighed on an analytical balance (brand Mettler, model AE-200) to determine their mean weight: a 5\% deviation was considered acceptable (COMISSÃO..., 1988).

\section{Hardness}

Hardness was determined by resistance to crushing or rupture under continuous pressure and was measured using a hardness tester (brand Erweka, model TBH-30). The result obtained was the mean of the resistance of the 10 tablets and was expressed in Newton (N) (COMISSÃO..., 1988). The minimum value recommended for hardness is $30 \mathrm{~N}$.

\section{Friability}

This parameter was determined by shock and friction. A friabilometer (Erweka, model TAR) was used. For this measurement, samples of 10 tablets were submitted to a $25 \mathrm{rpm}$ rotation speed for 4 minutes; a weight loss maximum value of 1 $\%$ was considered acceptable (UNITED..., 2009).

\section{Disintegration}

The disintegration time of a sample of six tablets was determined using a disintegration apparatus (Erweka, model ZT3) and distilled water at a temperature of $37 \pm 2{ }^{\circ} \mathrm{C}$ as the disintegration media (UNITED..., 2009); for effervescent tablets, a disintegration time limit of 5 minutes is considered acceptable.

\subsection{Effect of the compression force on probiotics viability}

Using distinct forces of compression, tablets with different hardness values were produced: $20 \mathrm{~N}, 40 \mathrm{~N}$, and $60 \mathrm{~N}$. Microorganisms were then counted to verify the correlation between hardness and viability.

\subsection{Effect of gastrointestinal fluids on probiotic viability}

For this analysis, $1.0 \mathrm{~g}$ of product (powder) was added to $9.0 \mathrm{~mL}$ of sterile simulated gastric fluids $(0.08 \mathrm{M} \mathrm{HCl}$, containing $0.2 \% \mathrm{NaCl}, \mathrm{pH} 2.0$ ). During incubation at $37^{\circ} \mathrm{C}$, a $1.0 \mathrm{~mL}$ aliquot was removed from the solution after 30,60 ,
90, and 120 minutes for determination of the viability of the microorganisms. Another $1.0 \mathrm{~mL}$ aliquot was removed at identical time intervals, which was added to $9.0 \mathrm{~mL}$ of simulated sterile intestinal fluids $\left(0.05 \mathrm{M} \mathrm{K}_{2} \mathrm{PO}_{4}, \mathrm{pH} 6.8\right.$, added with $0.6 \%$ of bile salts) and incubated at $37{ }^{\circ} \mathrm{C}$ for 150 minutes. After similar incubation periods, a $1.0 \mathrm{~mL}$ aliquot was used to verify the viability of the probiotic organisms, according to the modified methods developed by Rao, Shiwnarain and Maharaj (1989) and Thantsha et al. (2008).

\subsection{Statistical analysis}

The results of probiotic microorganism viability were assessed by ANOVA to detect possible statistically significant differences among the treatments, and the treatment means, wobtained from triplicate counts, were compared by the Tukey test, at 5\% probability, using the SAS-Agri statistical software program (CANTERI et al., 2001).

\section{Results and discussion}

\subsection{Formulation and development of powder and tablet effervescent probiotics}

Table 1 shows the data on the effect of tablet formulation ingredients on the viability of Lactobacillus acidophilus and Saccharomyces boulardii, using the $2^{(9-5)}$ factorial.

Table 2 shows the results of the main effects and statistical significance. The ingredients presenting negative effects for yeast growth were tartaric acid, citric acid, polyvinylpyrrolidone (PVP), aroma identical to the natural aroma of orange, and Stevia sweetener. Statistically significant differences were found only for the aroma identical to the natural aroma of orange $(\mathrm{p}=0.034145)$.

These results suggest that the ingredients with negative effects on yeast viability may decrease the concentration of microorganisms after the preparation of the drink containing probiotics, which would be less affected if these ingredients are present in the lowest possible concentration the powder formulation, especially in terms of the aroma concentration. However, it is important to emphasize that the product was developed to be consumed immediately after rehydration and should not be stored after preparation.

In Table 2, the concentration of L. acidophilus was negatively affected by the following ingredients: tartaric acid, citric acid, sucrose, and aroma, but aroma was the only ingredient with a significant effect $(p=0.048)$. The other ingredients, such as sodium bicarbonate, milk serum, Stevia sweetener; and stained mannitol had positive effects although these effects were not statistically significant. The only ingredient presenting a statistically significant effect was sodium bicarbonate. An increase in the concentration of these ingredients, in the composition of tablets or in the formulation of the powder product, would, and favor the stability of this bacterium in the product, and the content of sodium bicarbonate would be the most influential factor. However, as previously mentioned, the product should be consumed immediately after its preparation. 
Table 2. Estimated effects of different ingredients $(\mathrm{g})$ used in the formulation of water-soluble effervescent products (powder and tablets) on the cell viability of the yeast Saccharomyces boulardii and the lactic bacterium Lactobacillus acidophilus.

\begin{tabular}{ccccc}
\hline \multirow{2}{*}{ Treatments } & \multicolumn{2}{c}{ Saccharomyces boulardii } & \multicolumn{2}{c}{ Lactobacillus acidophilus } \\
\cline { 2 - 5 } & Effect & $\mathrm{p}$ & Effect & 0.000001 \\
Mean/Interc. & 9.90812 & 0.000000 & -1.76875 & 0.052793 \\
Tartaric acid & -0.29625 & 0,73704 & -1.79125 & 0.050639 \\
Citric acid & -0.88375 & 0.235046 & 3.64875 & 0.002539 \\
Sodium bicarbonate & 0.83375 & 0.259533 & 1.24625 & 0.140831 \\
PVP & -0.20375 & 0.771204 & -1.81875 & 0.048131 \\
Orange aroma & -1.82875 & 0.034145 & 0.95125 & 0.243085 \\
Stevia & -0.32125 & 0.648407 & -0.28125 & 0.715112 \\
Sucrose & 0.96625 & 0.199145 & 1.23375 & 0.144176 \\
Milk serum (whey) & 134375 & 0.091579 & 0.95875 & 0.239806 \\
Stained mannitol & 023625 & 0.736304 & & \\
\hline
\end{tabular}

After consideration of the ingredients' effects on the viability of probiotic microorganisms, the best formulation for the production of effervescent probiotic powder and effervescent probiotic tablets was determined, as shown in Table 3.

The industrial-scale production of the effervescent probiotic tablet was performed using talcum in its formulation, which is an anti-aggregating binder, diluent, and lubricant agent of capsules and tablets, and magnesium stearate, which is also a lubricant and an anti-binder excipient.

\subsection{Stability of effervescent probiotic products}

Table 4 shows the results of the viability of L. acidophilus and $S$. boulardii in powder and tablet effervescent forms after storage at $25^{\circ} \mathrm{C}$ for 60 days. For the effervescent probiotic powder, the data indicate only a small decrease in the microbial concentration during storage (less than 0.3 logarithmic cycles) for both probiotic strains. Nevertheless, for the effervescent probiotic tablets, there was a more expressive reduction in the concentration of the microorganisms (approximately 2.3 logarithmic cycles). This reduction occurred when the compression forces became relatively high on the tablets, which may have interfered with the viability of the microorganisms.

\subsection{Physical properties of tablets}

In order to be available on the market, tablets must undergo numerous studies and tests. Thus, pharmacopoeia determines the acceptable limits for the many quality criteria that the tablet formulations must possess to be approved. By meeting the established quality criteria, the maximum safety of the product is guaranteed and assurance that it can be safely consumed by people is provided.

The physical properties of the industrial tablet were obtained. The value for the mean weight was $0.948 \mathrm{~g}$, and the relative standard deviation was $0.047 \%$; therefore, the product met the requirements of the Brazilian Pharmacopoeia, which establishes a maximum variation of $5 \%$.

The mean hardness value obtained by the durometer was $38.7 \mathrm{~N} \mathrm{(30} \mathrm{N}$ is the minimum recommended hardness). The
Table 3. The ingredients used in the formulation of water-soluble effervescent products (powder and tablets) supplemented with the probiotic microorganisms Lactobacillus acidophilus and Saccharomyces boulardii.

\begin{tabular}{|c|c|c|c|}
\hline Ingredients & $\begin{array}{l}\text { Powder } \\
(\mathrm{g})\end{array}$ & $\begin{array}{l}\text { Laboratorial } \\
\text { tablets (g) }\end{array}$ & $\begin{array}{l}\text { Industrial } \\
\text { tablets }(\mathrm{g})\end{array}$ \\
\hline L. acidophilus ${ }^{*}$ & 10.0 & 10.0 & 10.0 \\
\hline S. boulardii ${ }^{*}$ & 10.0 & 10.0 & 10.0 \\
\hline Citric acid & 15.0 & 15.0 & 15.0 \\
\hline Sodium bicarbonate & 15.0 & 15.0 & 15.0 \\
\hline PVP & 0.0 & 9.3 & 9.3 \\
\hline Orange aroma & 1.0 & 1.0 & 1.0 \\
\hline Stevia & 1.0 & 1.0 & 1.0 \\
\hline Talcum & 0.0 & 0.0 & 2.0 \\
\hline Magnesium stearate & 0.0 & 0.0 & 0.6 \\
\hline Stained mannitol ${ }^{\star *}$ & 48.0 & 38.7 & 36.1 \\
\hline
\end{tabular}

${ }^{*}$ Sufficient to achieve a concentration of $10^{6} \mathrm{CFU}_{\mathrm{g}}{ }^{-1}$ of powder or $10^{7} \mathrm{CFU}_{\text {.tablet }}{ }^{-1}$. ${ }^{*}$ A $2.4 \mathrm{~mL}$ solution of $1 \%$ yellow twilight plus $3.6 \mathrm{~mL}$ of water in $30 \mathrm{~g}$ of mannitol and dried in a forced air circulation drying oven and ground in a mill (brand Coffee grinder, Model DCG-20).

Table 4. Viability of the probiotic microorganisms Lactobacillus acidophilus and Saccharomyces boulardii used in water-soluble effervescent formulations of powder and tablets stored for 0 (control), $15,30,45$, and 60 days at $25^{\circ} \mathrm{C}$.

\begin{tabular}{lcccccc}
\hline \multirow{2}{*}{ Product } & Probiotic & \multicolumn{5}{c}{ Storage time (days) } \\
\cline { 3 - 7 } & microorganisms & 0 & 15 & 30 & 45 & 60 \\
\hline \multirow{2}{*}{ Powder } & L. acidophilus & 5.15 & 5.08 & 6.11 & 5.48 & 4.92 \\
& S. boulardii & 6.70 & 6.43 & 6.60 & 6.69 & 6.62 \\
\hline \multirow{2}{*}{ Tablets } & L. acidophilus & 5.18 & 3.79 & 5.18 & 3.72 & 2.91 \\
& S. boulardii & 5.30 & 4.18 & 3.67 & 3.85 & 2.99 \\
\hline
\end{tabular}

hardness of a tablet is directly proportional to the logarithm of the compression force and inversely proportional to porosity (i.e., the higher the compression force, the lower the porosity and the higher the resistance, hardness, and time of degradation).

The value obtained for friability (degree of resistance that is manifested in relation to shock, friction, rolling, agitation, and 
attrition) was 0.066 , which corresponds to a loss of $0.66 \%$ of the initial weight. This value was within the standard maximum loss $(1 \%)$.

As for the disintegration time (which depends on the mechanism used as the disintegrating agent and how it acts on the tablet formulation), five of the 10 tablets assessed, disintegrated within 1 minute, and only one took 3 minutes to disintegrate, which agrees with the maximum time recommended (2 minutes).

Based on these results and analyses, it is clear that the probiotic tablet satisfies the technological requirements showing easy adaptations to the industrial process and adequate pharmacopoeial parameters (mean weight, hardness, friability, and disintegration).

\subsection{Effect of force compression on the viability of probiotics}

Table 5 shows the data regarding the effect of compression force on the viability of $S$. boulardii and L. acidophilus. The concentration of microorganisms decreased with an increase in hardness, and when the compression force reached over 20 $\mathrm{N}$, it interfered with the viability of the probiotics.

It is possible that there is a selection of a more compressionresistant microorganism population which remains viable above certain values, and apparently in this case, there is a critical compression value between $20 \mathrm{~N}$ and $40 \mathrm{~N}$ that selects a more resistant population since the probiotic counts remained practically the same at $40 \mathrm{~N}$ and $60 \mathrm{~N}$.

Depending on the pressure applied, the compression of cells may cause damages to the cell walls and membranes or even loss of viability. It is clear that under mechanical stress some cells cannot tolerate such compression. Initially, the increase in the force applied will primarily damage the cell wall, and when such pressure is further increased, it will also reach the cell membrane. Therefore, it has been observed that cellular viability decreases almost linearly with the applied compression force (CHAN; ZANG, 2002).

Conversely, Bora, Puri and Bansal (2009) observed a decline in spore formation in Bacillus coagulans probiotic with an increase in the compression force, indicating that survival also depends on the probiotic species and on the diluent used in the formulation. Maggi et al. (2000) also verified a reduction

Table 5. The effect of different compression forces, in Newton (N), on the viability of the probiotic microorganisms Lactobacillus acidophilus and Saccharomyces boulardii used in water-soluble effervescent formulations of powder and tablets.

\begin{tabular}{ccc}
\hline Treatments & S. boulardii & L. acidophilus \\
\hline Force before compression $(0 \mathrm{~N})$ & $10.86 \mathrm{a}^{*}$ & $10.51 \mathrm{~b}^{*}$ \\
Tablets under $20 \mathrm{~N}$ & $10.18 \mathrm{~b}$ & $10.80 \mathrm{a}$ \\
Tablets under $40 \mathrm{~N}$ & $8.93 \mathrm{c}$ & $8.19 \mathrm{~d}$ \\
Tablets under $60 \mathrm{~N}$ & $8.57 \mathrm{~d}$ & $8.39 \mathrm{c}$ \\
CV (\%) & 0.41 & 0.48 \\
\hline
\end{tabular}

${ }^{*}$ Means followed by the same letter in the column are not statistically different from each other by the Tukey test at $5 \%$ probability. in viability in different strains of lactobacillus during tablet production with other lyophilized strains.

\subsection{Effect of gastrointestinal juices on the viability of probiotics}

Tables 6 and 7 show the values for colony counts of $L$. acidophilus and $S$. boulardii after contact with artificial gastric and enteric juices, respectively.

During the 120 minutes period in which L. acidophilus was in contact with the gastric juice, there was a reduction in the logarithmic CFU number, which decreased from an initial value of 11.46 to the value of 9.58 after 120 minutes of contact. Moreover, when this probiotic was inoculated from the gastric juice to the intestinal juice, there was a significant decrease in the logarithmic CFU number from 9.58 to 5.25 due to the dilution that occurred in the test, most likely as a consequence of the sharp change in the $\mathrm{pH}$ from a value of 2.0 found in the gastric juice to a value of 6.8 found in the enteric juice, in addition to the effect that would be caused by the presence of bile salts.

However, it is worth mentioning that the tolerance mechanism to bile salts is not fully understood, and that it is difficult to define a maximum concentration to which a microorganism is able to endure (to be considered bile-resistant) because the concentration of this substance is not static, varying as a function of time and space (in different parts) of the intestine. It is known that the fluidity of membranes is temperaturedependent, allowing entry of larger concentrations of bile salts at higher temperatures; thus, the bactericidal effect of bile salts is dependent on the microorganism strain (MARTEAU et al., 1997; MADUREIRA et al., 2005; MARTINS et al., 2005).

Nevertheless, it is worth emphasizing that, during the 150 minutes in which the probiotic was exposed to the artificial enteric juice, the cell concentration remained constant since its population remained viable and tolerant of the bile salts.

Table 6. The viability of the probiotic microorganisms Lactobacillus acidophilus and Saccharomyces boulardii after 0 (control), 30, 60, and 120 minutes exposure to artificial gastric juice.

\begin{tabular}{cccccc}
\hline \multirow{2}{*}{ Microorganisms } & \multicolumn{5}{c}{$\begin{array}{c}\text { Number of probiotics in the gastric juice } \\
\text { (log. No. CFU.mL }{ }^{-1} \text { ) }\end{array}$} \\
\cline { 2 - 6 } & 0 & 30 & 60 & 90 & 120 \\
\cline { 2 - 6 } & 11.46 & 9.02 & 8.80 & 9.55 & 9.58 \\
\hline L. acidophilus & 10.22 & 8.61 & 8.64 & 9.54 & 9.82 \\
S. boulardii & 10.64 & & & \\
\hline
\end{tabular}

Table 7. The viability of the probiotic microorganisms Lactobacillus acidophilus and Saccharomyces boulardii after different time period exposure to artificial gastric juice.

Number of probiotics in the enteric juice (log. No. CFU.mL ${ }^{-1}$ )

\begin{tabular}{ccc}
\hline \multicolumn{3}{c}{ Exposure (minutes) } \\
\hline Microorganisms & 0 & 150 \\
\hline L. acidophilus & 5.26 & 4.16 \\
S. boulardii & 8.42 & 8.33 \\
\hline
\end{tabular}


Madureira et al. (2005) observed that when pre-incubated in artificial gastric juice for 120 minutes, Lactobacillus acidophilus strain LAC-1 showed a decrease in the number of viable cells by approximately three logarithmic cycles, which also occurred during the 30 minutes of subsequent contact with the bile salts.

Conversely, the yeast Saccharomyces boulardii showed only a small decrease in CFU counts after contact with artificial gastric juice for 120 minutes. However, when inoculated with artificial enteric juice, the cell concentration partially decreased because of the dilution demanded by the test, remaining practically constant during the 150 minutes timeframe, which indicates a higher resistance of yeast compared to that of bacteria.

\section{Conclusions}

Under the experimental conditions and considering the results obtained, the following conclusions are drawn:

- The development of Lactobacillus acidophilus is negatively (but not significantly) affected by tartaric acid, citric acid, and sucrose; however, the aroma similar to that of orange exerts negative effects on the development of this bacterium;

- Milk serum, Stevia sweetener, polyvinylpyrrolidone (PVP), and stained mannitol have a positive (but not significant) effect on the growth of Lactobacillus acidophilus, despite the significant effect of sodium bicarbonate on the growth of this bacterium;

- Tartaric acid, citric acid, polyvinylpyrrolidone (PVP), Stevia sweetener, and aroma ingredients that are similar to that of orange, have negative effects on the growth of Saccharomyces boulardii;

- Sodium bicarbonate, sucrose, milk serum, and stained mannitol have positive effects on the growth of Saccharomyces boulardii although they are not statistically significant;

- After two months of storage at $25{ }^{\circ} \mathrm{C}$ in closed plastic packing, it was observed a more expressive decrease in the probiotic CFU counts in the formulations of effervescent tablets than in the powder formulations;

- A decrease in the probiotic microorganism concentrations with an increased compression force over 20 Newton was observed;

- Higher stability of Saccharomyces boulardii in relation to Lactobacillus acidophilus was observed during the exposure of the probiotic microorganisms to gastric and enteric fluids;

- Formulation of powder effervescent probiotics is more promising from an industrial point of view because of the better viability of the product during storage, in addition to the fact that the production of the powder compared with the production of tablets requires the use of fewer ingredients (talcum, magnesium stearate and PVP) and fewer pieces of equipment (compressor, durometer, disintegrator, and friabilometer), which means smaller investment.

\section{Acknowledgements}

The authors are grateful for the financial support provided by the Conselho Nacional e Desenvolvimento Científico e Tecnológico (CNPq).

\section{References}

BIGLIARDI, B.; GALATI, F. Innovation trends in the food industry: the case of functional foods. Trends in Food Science \& Technology, v. 31, p. 118-129, 2013. http://dx.doi.org/10.1016/j.tifs.2013.03.006

BORA, P. S.; PURI, V.; BANSAL, A. K. Physicochemical properties and excipient compatibility studies of probiotic bacillus coagulans spores. Scientific Pharmaceuticals, v. 77, p. 625-637, 2009. http:// dx.doi.org/10.3797/scipharm.0904-01

BUTS, J-P. Ejemplo de un medicamento probiótico: Saccharomyces boulardii liofilizada. Revista de Gastroenterología del Perú, v. 25, n. 2, p. 176-188, 2005. PMid:16021204.

CANTERI, M. G. et al. SASM - Agri: sistema para análise e separação de médias em experimentos agrícolas pelos métodos Scoft - Knott, Tukey e Duncan. Revista Brasileira de Agrocomputação, v. 1, n. 2, p. 18-24, 2001.

CHAIKHAM, T. et al. Lactobacillus acidophilus LA5 or Lactobacillus casei 01 in processed longan juices on exposure to simulated gastrointestinal tract. Jounal of the Science of Food and Agriculture, v. 93, n. 9, p. 2229-2238, 2013. PMid:23401169. http:// dx.doi.org/10.1002/jsfa.6030

CHAN, E. S.; ZHANG, Z. Encapsulation of Probiotic Bacteria Lactobacillus Acidophilus by Direct Compression Food and Bioproducts Processing, v. 80, p. 78-82, 2002

COMISSÃO PERMANENTE DE REVISÃO DA FARMACOPÉIA BRASILEIRA DEFINITION. Farmacopéia brasileira. 4. ed. São Paulo: Atheneu, 1988. parte 1.

FOOD AND AGRICULTURE ORGANIZATION OF THE UNITED NATIONS - FAO; WORLD HEALTH ORGANIZATION - WHO. Guidelines for the Evaluation of Probiotics in Food. Report of a Joint FAO/WHO Working Group on Drafting Guidelines for the Evaluation of Probiotics in Food. 2002. Disponível em: <http:// www.who.int/foodsafety/fs_management/en/probiotic_guidelines. pdf $>$. Acesso em: 28 jun. 2009.

FRANCO, B. D. G. M.; LANDGRAF M.; DESTRO, M. T. Microbiologia dos alimentos. São Paulo: Atheneu, 1996.

GOMES, A. M. P.; MALCATA, F. X. Agentes probióticos em alimentos: aspectos fisiológicos e terapêuticos, e aplicações tenológicas. Biotecnologia Alimentar: Boletim de Tecnologia, v. 101, p. 1222, 2002.

KOMATSU, T. R.; BURITI, F. C. A.; SAAD, S. M. I. Inovação, persistência e criatividade superando barreiras no desenvolvimentos de alimentos probióticos. Revista Brasileira de Ciências Farmacêuticas v. 44, n. 3, p. 329-347, 2008. http://dx.doi. org/10.1590/S1516-93322008000300003

MADUREIRA, A. R. et al. Survival of probiotic bactéria in a whey cheese vector submitted to environmental conditions prevailing in the gastrointestinal tract International Dairy Journal, v. 15, p. 921-927, 2005. http://dx.doi.org/10.1016/j.idairyj.2004.08.025

MAGGI, L. et al. Technological and biological evaluation of tablets containing different strains of lactobacilli for vaginal administration. European Journal of Pharmaceutics and Biopharmaceutics, v. 50, p. 389-395, 2000. http://dx.doi.org/10.1016/S0939-6411(00)00121-1

MARTEAU, P. et al. Survival of lactic acid bacteria in a dynamic model of the stomach and small intestine: validation and the effects of bile. 
Journal of Dairy Science, v. 80, p. 1031-1037, 1997. http://dx.doi. org/10.3168/jds.S0022-0302(97)76027-2

MARTINS, F. S. et al. Estudo do potencial probiótico de linhagens de saccharomyces cerevisiae através de testes in vitro. Revista de Biologia e Ciência da Terra, v. 5, n. 2, 2005.

MARTINS, F. S. et al. Inhibition of tissue inflammation and bacterial translocation as one of the protective mechanisms of Sacharomyces boulardii against Salmonella infection in mice. Microbes and Infection, v. 15, p. 270-279, 2013. PMid:23376166. http://dx.doi. org/10.1016/j.micinf.2012.12.007

MOUNTZOURIS, K. C. et al. Effects of Lactobacillus acidophilus on gut microflora metabolic biomarkers in fed and fasted rats. Clinical Nutrition, v. 28, p. 318-324, 2009. PMid:19223094. http://dx.doi. org/10.1016/j.clnu.2009.01.009

OLIVEIRA, M. N. et al. Aspecto tecnológico de alimentos funcionais contendo probióticos. Brazilian Journal of Pharmaceutical Sciences, v. 38, n. 1, p. 1-21, 2002
RAO, A. V.; SHIWNARAIN, N.; MAHARAJ, L. Survival of microencapsulated Bifidobacterium pseudolongum in simulated gastric and intestinal juices. Canadian Institute of Food Science and Technology Journal, v. 22, p. 345-349, 1989. http://dx.doi. org/10.1016/S0315-5463(89)70426-0

TENNEY, D. Acidophilus. Grand Rapids: Woodland Publishing, 1996. $26 \mathrm{p}$.

THANTSHA, M. S. et al. Supercritical carbon dioxide interpolymer complexes improve survival of $\mathrm{B}$. longum Bb-46 in simulated gastrointestinal fluids. International Journal of Food Microbiology, v. 129, p. 88-92, 2008. PMid:19062122. http://dx.doi.org/10.1016/j. ijfoodmicro.2008.11.001

UNITED STATES PHARMACOPEIAL. The United States pharmacopeia 32: the national formulary 27. Rockville: United States Pharmacopeial convention, 2009. 